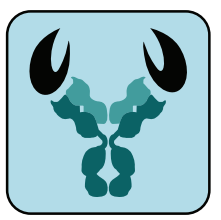

Journal of Experimental \&

Clinical Cancer Research

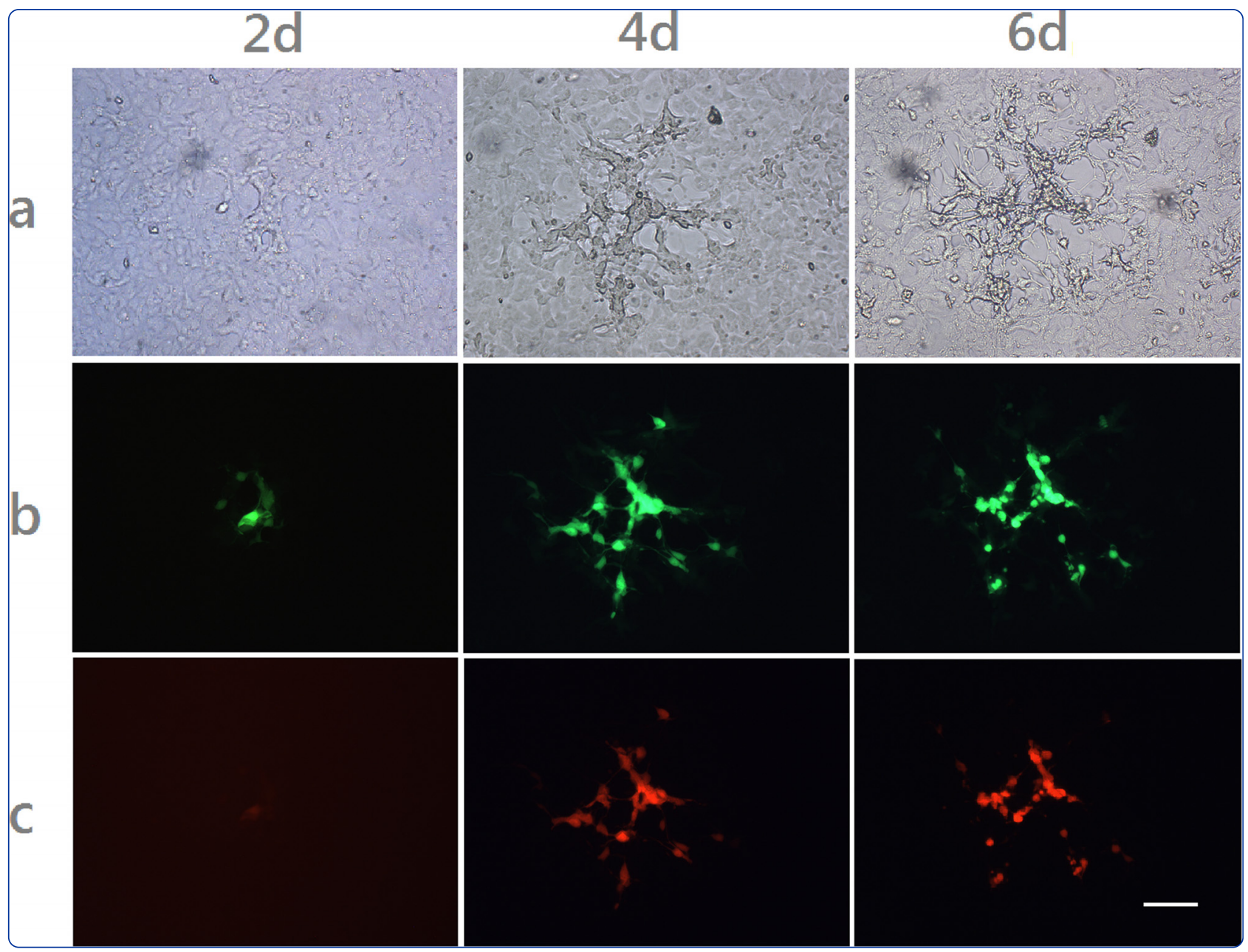

Oncolytic tanapoxvirus expressing FliC causes regression of human colorectal cancer xenografts in nude mice

Conrad et al.

C Biomed Central

Conrad et al. Journal of Experimental \& Clinical Cancer Research (2015) 34:19

DOI 10.1186/s13046-015-0131-z 


\title{
Oncolytic tanapoxvirus expressing FliC causes regression of human colorectal cancer xenografts in nude mice
}

\author{
Steven J Conrad ${ }^{1}$, Mohamed El-Aswad ${ }^{1}$, Esaw Kurban', David Jeng ${ }^{1}$, Brian C Tripp', Charles Nutting1,
} Robert Eversole ${ }^{1}$, Charles Mackenzie ${ }^{2}$ and Karim Essani ${ }^{i^{*}}$

\begin{abstract}
Colorectal cancers are significant causes of morbidity and mortality and existing therapies often perform poorly for individuals afflicted with advanced disease. Oncolytic virotherapy is an emerging therapeutic modality with great promise for addressing this medical need. Herein we describe the in vivo testing of recombinant variants of the tanapoxvirus (TPV). Recombinant viruses were made ablated for either the 66R gene (encoding a thymidine kinase), the $2 L$ gene (encoding a TNF-binding protein), or both. Some of the recombinants were armed to express mouse chemotactic protein 1 (mCCL2/mMCP-1), mouse granulocyte-monocyte colony stimulating factor (mGM-CSF), or bacterial flagellin (FliC). Tumors were induced in athymic nude mice by implantation of HCT 116 cells and subsequently treated by a single intratumoral injection of one of the recombinant TPVs. Histological examination showed a common neoplastic cell type and a range of immune cell infiltration, necrosis, and tumor cell organization. Significant regression was seen in tumors treated with virus TPV/ $\triangle 2 L / \Delta 66 R / f l i C$, and to a lesser extent the recombinants TPV/ $\Delta 2 L$ and TPV/ $666 R$. Our results suggest that oncolytic recombinants of the TPV armed with activators of the innate immune response may be effective virotherapeutic agents for colorectal cancers in humans and should be explored further to fully realize their potential.
\end{abstract}

\section{Introduction}

The projected toll exacted by colorectal cancer in humans (hCRC) in 2014 is more than 50,000 deaths, with nearly 100,000 new diagnoses in the United States alone $[1,2]$. Globally, it is the second-most common cancer in women (after breast cancer) and the third-most common in men (after lung and prostate cancers, respectively) [3]. More than $50 \%$ of those stricken by hCRC will experience metastatic sequelae to the liver or, less often, to the lungs $[4,5]$. Established therapies are often inadequate for patients with advanced disease (stages III or IV, lymph node positive and/or metastatic) where five-year survival rates fall to less than $20 \%$ [6]. In the United States the five-year survival rate for patients with all stages of hCRC improved by 14\% between 1977 and 2006 , from $51 \%$ to $65 \%$ [6]. This improvement is an

\footnotetext{
*Correspondence: karim.essani@wmich.edu

'Laboratory of Virology, Department of Biological Sciences, Western Michigan University, Kalamazoo, Ml 49008, USA

Full list of author information is available at the end of the article
}

aggregate effect of better detection techniques which resulted in earlier detection, improvements in therapeutic efficacy, and a slightly reduced incidence [2]. Still, the grim statistics cited earlier hold true, and new treatments and treatment modalities are desperately needed.

The idea that replication-competent viruses could be used to kill tumors in vivo was formally stated over a century ago (reviewed in [7]), but the first modern (i.e., genetically engineered) oncolytic virus (OV) was reported relatively recently [8]. Progress in the design of OVs has been rapid [9], and replication-competent oncolytic variants of several viral families have been tested against hCRC and other cancerous growths in clinical trials. These include the adenoviruses [10,11], herpesviruses $[12,13]$, poxviruses $[14,15]$ and reoviruses [16].

Each family of viruses has a unique biology and replication strategy, and this uniqueness presents a distinct set of advantages and disadvantages from the standpoint of $\mathrm{OV}$ design. The poxviruses have several inherent qualities that make them well-suited for use as OVs, and 
have been described as "oncolytic battleships" [17]. This is because poxvirus genomes are able to accommodate a large amount of added genetic material [18], and because all poxviruses come with a built-in array of offensive and defensive capabilities (reviewed in [19]). Poxvirus genomes encode a variety of immunomodulatory proteins devoted to hiding infection-associated cell-surface epitopes from host immunesurveillance, the inhibition and evasion of some host immune and inflammatory responses, and the disruption of signals from the extracellular environment by means of virally-encoded peptides which mimic or neutralize host cytokines and cytokine receptors [19-24].

The OVs described in this study are recombinant variants of the tanapoxvirus (TPV), a member of the genus Yatapoxvirus. Several features of the TPV make it an attractive candidate for oncolytic virotherapy. Infected humans experience only a mild and self-limiting febrile illness, in part because TPV infection is normally confined to peripheral areas of the body [25]. Apart from areas in equatorial Africa (where it is endemic) humans are immunologically naïve to TPV [26,27]. Additionally, TPV has never been observed to transmit from person to person, a highly desirable safety feature in an oncolytic virus.

Ablation of the viral thymidine kinase (TK) is a common strategy to increase oncoselectivity in several OV types, especially the herpesviruses and poxviruses $[8,28]$ ). This is because TK activity in neoplastic cells is constitutively high, due to the action of cellular TK1. High TK activity in neoplastic cells is in contrast to normal cells, where TK activity levels peak during the $S$ phase of the cell cycle and are nearly undetectable at other times [29-31]. Cellular TK activities are significant from an OV design perspective because the cellular TK1 catalyses a critical step in nucleotide synthesis, the conversion of thymidine to thymidine monophosphate [29]. For this reason, cancerous cells express TK1 throughout the cell cycle, and as a result tend to have large cytoplasmic pools of thymidine monophosphate available at all times. This differential activity has been exploited to provide a degree of cancer cell selectivity in $t k$-ablated OVs. Successful examples of this strategy include the vaccinia virus (VACV) recombinants GLV-1 h68 [32,33].

OVs which express transgenes intended to increase their oncolethality are referred to as "armed" [34,35]. Some of the TPV recombinants described herein were armed to express either mouse $(\mathrm{m})$ granulocyte-monocyte colony stimulating factor (mGM-CSF), mouse macrophage chemotactic protein 1 (mCCL2, also referred to as mMCP-1), or bacterial flagellin (FliC, the product of the $\mathrm{fliC}$ gene in Salmonella enterica). Although mammalian immune system is interdependent and integrated, both cytokines (GM-CSF and CCL2) and bacterial flagellin (FliC) primarily stimulate the innate immune system.
Hence, there appears to be no distinct advantage in testing the therapeutic transgenes, described in this study, in syngeneic or transgenic models at this stage. Nude mice have an intact and functional innate immune system, but lack a functional adaptive immune response. Though the adaptive immune response in nude mice is ineffective, immature $\mathrm{CD} 3+\mathrm{T}$ cells have been reported [36]. We, therefore, concluded that the use of nude mice in this study is valid to report the impact of innate immunity on oncolytic virotherapy.

CCL2 is a pleiotropic chemokine and is known to exert effects beyond its primary effect, including bone remodeling and bone disease [37] and the atopic response [38,39]. CCL2 has been reported to enhance host anti-tumor immune response elicited by some OVs [40].

Expression of GM-CSF by an OV, or its introduction to the tumor environment by other means is a wellestablished strategy in OVs, anticancer vaccines and vaccine adjuvants [41-43]. There are many examples of the use of GM-CSF as part of a strategy to engineer GMCSF-expressing tumor cells (autologous or allogeneic) and re-introduce them into the tumor environment [44,45]. Many replication-competent OVs have been armed to express GM-CSF [46-49].

Polymerized flagellin is the main component of the bacterial flagellum [50,51]. The flagellin used in this study was the product of the Salmonella enterica serovar typhimurium gene, fliC. FliC and other bacterial flagellins are cognate ligands of the toll-like receptor 5 (TLR5) [52,53], and are strong activators of the innate immune response in mammalian cells via MyD88dependent intracellular signaling and, ultimately, the activation of transcription factor NFKB [54]. TLR 5 activation has been shown to substantially increase necrosis and lead to tumor regression [55]. Here we describe the oncolytic ability of TPV recombinants to regress hCRC xenografted tumors in athymic nude mice.

\section{Methods}

\section{Cells, reagents and viruses}

OMK, HCT 116, COLO 205, SW1463 and WiDr cells were purchased from the American Type Culture Collection (ATCC product numbers CRL-1556, CCL-247, CCL-222, CCL-234 and CCL-218, respectively). OMK (Owl Monkey kidney) cells were used for all virus amplification and viral titrations. All cell lines were propagated in complete growth medium consisting of Dulbecco's Modified Eagle's Medium (Gibco/Life Technologies) supplemented with $10 \%$ (vol/vol) fetal bovine serum (FBS) (Atlanta Biologicals), $2 \mathrm{mM}$ L-glutamine (Sigma-Aldrich) and $50 \mu \mathrm{g} / \mathrm{ml}$ gentamicin sulfate (AMRESCO). After virus infection all cell monolayers were maintained in maintenance medium which was identical to growth medium except that the concentration of FBS was reduced to $2 \%$. All 
cells were incubated at $37^{\circ} \mathrm{C}$ in a $5 \% \mathrm{CO}_{2}$ atmosphere. Cell counting and cell viability assays were done with an Improved Neubauer hemacytometer using $0.2 \%$ (wt/vol) trypan blue in a normal saline solution. Wild-type TPV (Kenya strain) was originally a gift from Dr. Joseph Esposito (Centers for Disease Control, Atlanta, GA, USA). It was genetically modified in the laboratory of G. McFadden to express the fluorescent reporter enhanced green fluorescent protein (EGFP), but with no other modifications.

\section{The p2KO vector}

For the construction of the $\mathrm{p} 2 \mathrm{KO}$ vector we used the commercially-available plasmid cloning vector pBluescript II $\mathrm{KS}(+)$ as starting material. This cloning vector is a high-copy number plasmid which features ampicillin selection and has a multiple cloning sites which contains many useful and unique restriction endonucleases sites. We inserted two identical synthetic early/late promoters [56] between the unique Xba I and Xma I sites and the Xma I and EcoRI sites, in each case using long primers to include the 52-bp promoter and the small sequence between the 3 ' - end of the promoter and the start codon on the transgene (expressed transgene or fluorescent reporter). Flanking sequences from the wild-type TPV genome were inserted between unique Sac I and Not I restriction sites (left flank) and unique EcoR I and Hind III restriction sites (right flank). Flanking regions were ligated into the p2KO vector between the Sac I and Not I restriction sites on the $5^{\prime}$ - (left) flank, and between the EcoR I and Hind III restriction sites on the 3'- (right) flank. In this way the $\mathrm{p} 2 \mathrm{KO}$ expression cassette could be guided to a specific point in the viral genome by the use of viral genomic flanking sequences, resulting in a targeted ablation of the desired gene(s) with the simultaneous expression of a fluorescent reporter and (if desired) an expressed transgene (in this study mCCL2, mGMCSF or $f l i C)$. The relevant primers are documented in Table 1.

The mCCL2 cDNA clone ORF was purchased as an ORF-bearing plasmid (Sino Biological, Incorporated). The cDNA clone ORF of mGM-CSF was a gift from Dr. Grant McFadden. The mCCL2, mGM-CSF and fliC ORFs were amplified from their vectors by PCR and given BamHI and XmaI restriction sequences on the 5'and 3 '- termini of the product amplicons. They were ligated into the $\mathrm{p} 2 \mathrm{KO}$ poxvirus vector in the expressed transgene insertion site. All resulting plasmids were confirmed by DNA sequencing.

The $\mathrm{p} 2 \mathrm{KO}$ vector was intended to provide a rapid and reliable way to simultaneously ablate any desired TPV gene(s) and replace the ablated gene(s) with an expressed transgene (if desired) and an expressed fluorescent reporter. It was completely modular in that the ORFs in either the expressed transgene or the
Table 1 Primers used in the construction of the p2KO ablation/insertion vector

\begin{tabular}{|c|c|}
\hline Primer name & Sequence \\
\hline \multicolumn{2}{|l|}{ left flank } \\
\hline 66R L Sacl (f) & 5'-AATGGATCACATAAAGGAGCTCTTAACG-3' \\
\hline $66 \mathrm{R}$ L Notl (r) & 5'- CAGAAAACATGCGGCCGCATATAATCT-3' \\
\hline \multicolumn{2}{|l|}{ right flank } \\
\hline 66R R EcoRl & 5'-GGAGATGAACAAGAAATAGAATTCATAGG-3' \\
\hline 66R R HindIII & 5'- CTGTTCTTTATCACAAGCTTCTATCGGGTG-3' \\
\hline \multicolumn{2}{|l|}{ mGM-CSF } \\
\hline hmGMCSF BamHI (f) & $\begin{array}{l}\text { 5'-TAGGCCTGGGATCCGATCCACCGGTCGCCACCAT } \\
\text { GTGGCTGCAGA-3' }\end{array}$ \\
\hline mGMCSF Xmal (r) & 5'-CTCATCAATGTATCTTATCATCCCGGGCTAGCT-3' \\
\hline \multicolumn{2}{|l|}{$\mathrm{mCCL} 2 / \mathrm{MCP}-1$} \\
\hline mMCP-1 BamHI (f) & $\begin{array}{l}\text { 5'-TAGGCCTGGGATCCGATCCACCGGTCGCCACCA } \\
\text { TGCAGGTCCCTG-3' }\end{array}$ \\
\hline mMCP-1 Xmal (r) & 5'-CGGCGATCCCCGGGAGATACTAGTTCAC-3' \\
\hline \multicolumn{2}{|l|}{ fliC (S. typhimurium) } \\
\hline FliC BamHI (f) & 5'-ACCCGGGGATCCTCTAGAAATAATTTTG-3' \\
\hline FliC Xmal (r) & 5'-GGAGCTCGAACCCGGGTCCTTAAC-3' \\
\hline M13 (f) & 5'-TGTAAAACGACGGCCAGT-3' \\
\hline M13 (r) & 5'-CAGGAAACAGCTATGACC-3' \\
\hline \multicolumn{2}{|l|}{$\begin{array}{l}66 R \text { ablation } \\
\text { verification }\end{array}$} \\
\hline $66 \mathrm{R} \operatorname{int}(\mathrm{f})$ & 5'- CGGTATCAAATTGCTAGGTATACTTGC-3' \\
\hline $66 \mathrm{R}$ int $(r)$ & 5'- CTCCAATTCGTTTAGAAAACGATGCG-3' \\
\hline \multicolumn{2}{|l|}{$\begin{array}{l}2 L \text { ablation } \\
\text { verification }\end{array}$} \\
\hline $2 L \operatorname{int}(f)$ & 5'- CCATTGCATCCTTCAGAACAAG-3' \\
\hline $2 \mathrm{~L}$ int $(r)$ & 5'- GCATAACTITAAAATATAATTATACTGTTACG-3' \\
\hline \multicolumn{2}{|l|}{$\begin{array}{l}\text { PCR template } \\
\text { control }\end{array}$} \\
\hline $136 \mathrm{R}$ int $(f)$ & 5'- GTATTTATGTACTGTTTCAACTAACAAAAGC-3' \\
\hline $136 \mathrm{R}$ int $(r)$ & 5'- CCTTTAGGTGTTAGGATATATCAATTATACAG-3' \\
\hline
\end{tabular}

Where applicable the inserted restriction endonucleases sites are indicated by italicized text and start codons within the forward primer and/or the stop codons within the reverse primer are shown by gray shading. The 66R int $(\mathrm{f} / \mathrm{r})$ and $2 \mathrm{~L}$ int $(\mathrm{f} / \mathrm{r})$ primer sets are verification primers used to verify $66 \mathrm{R}$ and/or $2 \mathrm{~L}$ ablations, while the $136 \mathrm{R}$ gene is present in all viruses and is used as a positive control for the quality of the template DNA in PCR reactions.

fluorescent reporter insertion sites could be easily removed and replaced with any other ORFs (Figure 1). The overall sequence of the base vector (i.e., with the mCherry fluorescent reporter but without an inserted expressed transgene) was verified by DNA sequencing of an amplicon produced by PCR amplification of the region between the M13 forward and reverse primer binding sequences. The insertion of ORFs encoding $\mathrm{mCCL2}$, mGM-CSF or $f l i C$ was verified by DNA sequencing of the $\mathrm{p} 2 \mathrm{KO}$ plasmid vector to ensure correct placement and orientation before they were used in the 


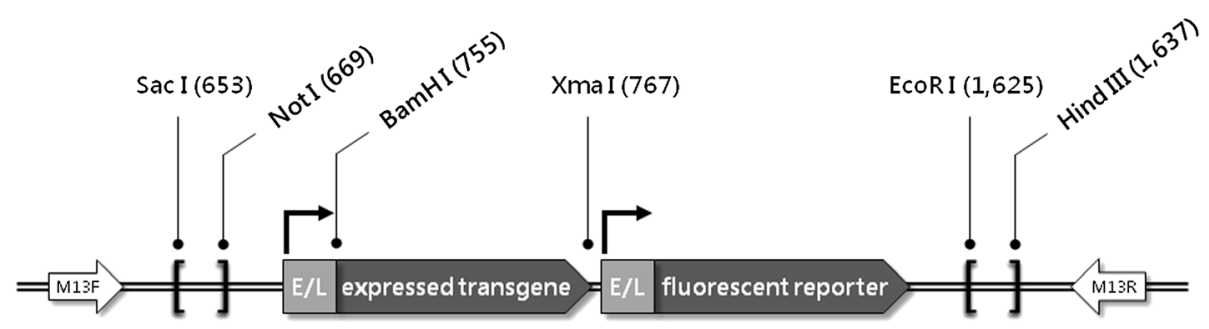

Figure 1 The poxvirus ablation/insertion vector p2KO. Separate but identical poxvirus early/late synthetic promoters allowed for simple and targeted ablation of selected gene(s) with the simultaneous expression of the fluorescent reporter mCherry with or without the expression of an additional expressed transgene. The left and right flanks are bounded by pairs of unique restriction sites (Sac I and Not I for the left flank, EcoR I and Hind III for the right flank). The expressed transgene ORF is bounded by unique a 5'- BamH I and a 3'- Xma I restriction site. These allow for the simple and directional ligation of PCR amplicons bounded by the appropriate restriction sites. Numbers in small type refer to nucleotide positions within the $\mathrm{p} 2 \mathrm{KO}$ vector.

transfection/infection procedure. The recombinant viruses were verified to be deleted for the core regions of $2 L, 66 R$, or both by agarose gel analysis of PCR products using recombinant viral DNA as template (Table 2). Primer sets (Table 1) which amplified sequences internal to the ablated regions in the $66 R$ and $2 L$ genes were used to verify the absence of these genes in the recombinant TPVs made. A similar primer set which amplified a region of the $136 R$ gene was used to verify the suitability of the DNA preparation for PCR amplification. The predicted amplicon size for the $66 R$ internal primer set is $379 \mathrm{bp}$; the predicted amplicon size for the $2 L$ primer set is $904 \mathrm{bp}$; and for the $136 \mathrm{R}$ control primer set the amplicon size is 531 bp. A recombinant virus with an ablated gene failed to produce a PCR product when probed for that particular gene with these primer sets (Figure 2).

The p2KO expression cassette (left and right flanks, plus the intervening ORFs and the promoters) was transferred to the viral genome through a homologous recombination double-crossover event during transfection/infection. During transfection/infection, poxvirus genomes present in the cytoplasmic space of infected

\section{Table 2 Viruses made using the p2KO ablation/insertion} vector

\begin{tabular}{|c|c|c|c|}
\hline TPV recombinant & Gene ablated & Gene added & Reporter(s) \\
\hline TPV/egfp & --- & EGFP & \\
\hline TPV/ $\Delta 66 R$ & $66 R$ & --- & mCherry \\
\hline TPV/D66R/mGM-CSF & $66 R$ & $\mathrm{mGM}-\mathrm{CSF}$ & mCherry \\
\hline $\mathrm{TPV} / \triangle 66 R / \mathrm{m} M C P-1$ & $66 R$ & $\mathrm{~m} M C P-1$ & mCherry \\
\hline TPV/A66R/fliC & $66 R$ & flic & mCherry \\
\hline $\mathrm{TPV} / \triangle 2 \mathrm{~L}$ & $2 L$ & --- & mCherry \\
\hline TPV/2L/A66R/fliC & $66 R, 2 L$ & flic & EGFP, mCherry \\
\hline
\end{tabular}

All viruses expressed the fluorescent reporter mCherry with the exception of TPV/egfp, which was modified to express fluorescent reporter EGFP but had no other genetic modifications. "Gene added" refers to an ORF added and expressed other than the fluorescent reporter. The TPV/ $\triangle 2 L / \triangle 66 R /$ fliC double-ablated recombinant TPV expressed both EGFP and mCherry. cells were in close proximity to the transfected $\mathrm{p} 2 \mathrm{KO}$ vector, whose flanking sequences allowed for a targeted double-crossover homologous recombination event. During the double-crossover event, the region between the flanking sequences on the $\mathrm{p} 2 \mathrm{KO}$ vector was transferred to the viral genome, simultaneously ablating the intervening viral sequence and resulting in a recombinant viral genome which contains the fluorescent reporter and (if desired) an additional ORF, both of which are now driven by synthetic early/late promoters derived from VACV.

\section{Transfection/infection}

The transfection/infection procedure used to produce the recombinant viruses in this study has been described previously [57-59]. Briefly, OMK cells were transfected using jetPRIME transfection reagent (PolyPlus Transfection SA) at a concentration of $1 \mu$ l transfection reagent per $\mu \mathrm{g}$ of purified $\mathrm{p} 2 \mathrm{KO}$ plasmid vector according to the manufacturer's protocol. At approximately five hours post transfection, OMK cell monolayers were inoculated with 1 plaque-forming unit (pfu) per cell of wild-type TPV-Kenya strain (no fluorescent reporter expressed). At five days post-inoculation the infected monolayers were scraped with a cell scraper on ice and the lysates were processed by three cycles of freezing and thawing at $-80^{\circ} \mathrm{C}$ followed by 15 seconds of sonication at $4^{\circ} \mathrm{C}$. Samples were serially diluted and plated onto freshlyseeded OMK cell monolayers at approximately 90\% confluence and overlaid with maintenance medium containing $0.5 \%$ methylcellulose. Fluorescent, well-separated plaques were picked and each pick subjected to at least three rounds of plaque purification to produce a virus preparation which contained no visible wild type (nonfluorescent) plaques. Samples were considered pure if no wild-type plaques were visible in culture and no relevant fragments of wild-type TPV genomic DNA were detectable by PCR.

Because it was necessary to ablate two discrete genetic loci (the $2 L$ and $66 R$ genes) the TPV/ $\Delta 2 L / \Delta 66 R / f l i C$ 


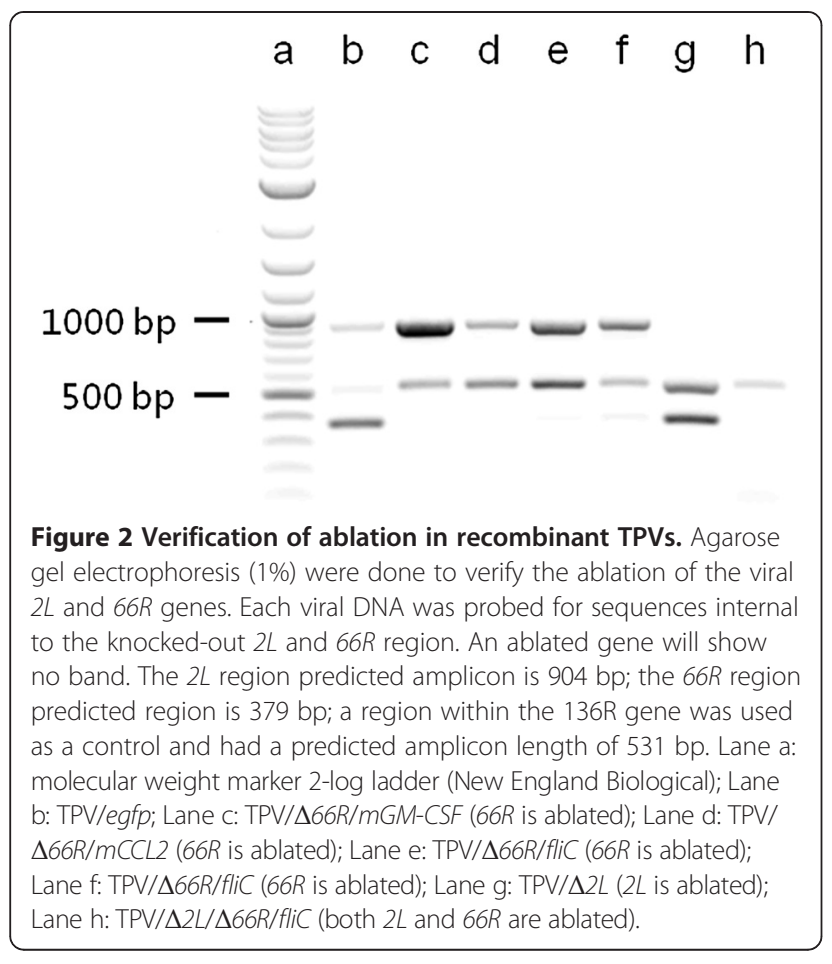

virus was made using an additional iteration of the transfection/infection procedure. Using a plasmid (generously provided by J. Barrett) which contained a single VACV early/late synthetic promoter driving expression of EGFP, we inserted sequences flanking the $66 R$ gene, resulting in a $66 R$-ablation vector. This vector was used in the transfection/infection procedure with wild-type TPV (Kenya) to make TPV/ $66 R /$ egfp. Selection was enabled by the expression of EGFP against a nonfluorescent background. After 3X plaque purification, this EGFP-expressing virus was used in place of the wild-type TPV in a second transfection/infection with a $\mathrm{p} 2 \mathrm{KO}$ ablation/insertion vector which contained sequences flanking the $2 L$ gene, the $f l i C$ ORF, and the mCherry fluorescent reporter. Selection was enabled by the expression of mCherry-expressing plaques against a background of EGFP expression.

\section{Confirmation of viral transgene expression}

Verification of FliC expression was done by Western blot of virus infected cell lysates. Proteins were transferred to a PVDF membrane (Millipore) and probed with an anti-FliC monoclonal antibody (BioLegend) at a 1:2000 dilution ( $\mathrm{vol} / \mathrm{vol})$. Powdered milk $5 \%$ (wt/vol) was used as the blocking agent. The secondary antibody was a monoclonal anti-mouse IgG conjugated to horseradish peroxidase (Abcam), used at a 1:2500 dilution. Visualization was by enhanced chemiluminescence (ECL) (Thermo Scientific/Pierce). TPV recombinants containing the $\mathrm{p} 2 \mathrm{KO}$ vector's fluorescent reporter but without any other expressed transgenes (empty vectors) and uninfected cells served as controls in these experiments. Verification of mCCL2 and mGM-CSF expression was done by Luminex multianalyte cytokine detection assay (University of Maryland cytokine core laboratory), both in cell lysates and supernatants from virus infected cells. Samples for analysis were prepared by infecting semiconfluent OMK cell monolayers in $60 \mathrm{~mm}$ tissue culture dishes with TPV/ $\triangle 66 R / \mathrm{mCCL} 2, \mathrm{TPV} / \Delta 66 R / \mathrm{mGM}-C S F$ or TPV $/ \Delta 2 L / \Delta 66 R / f l i C$ using $10 \mathrm{pfu} / \mathrm{cell}$. Supernatant (3 $\mathrm{ml} /$ dish) and cytoplasmic extracts were prepared at the indicated times post-infection. Uninfected cell lysates and cells infected with virus not expressing mCCL2, mGM-CSF, or FliC served as controls for confirmation of expression experiments.

\section{Cell density determinations}

Four human colorectal cancer cell lines and the OMK cell control were separately inoculated into 12-well plates ( 3 wells per cell line) such that one day later the cells were 90\% confluent. Each well was trypsinized, counted and scored for viability by trypan blue exclusion. This was done to ensure that pfu/cell for each cell line would be accurate.

\section{Virus titration}

To assay the number of viable virions present in a sample, a plaque assay was used as previously described [60]. Briefly, virus samples were subjected to three rounds of freezing and thawing at $-80^{\circ} \mathrm{C}$, sonicated for 15 seconds on ice, serially diluted in maintenance medium and inoculated onto nearly confluent OMK cell monolayers in 6-well plates. Virus was allowed to adsorb at room temperature with gentle rocking for one hour. The inoculum was then removed and each well washed two times with $1 \mathrm{ml}$ of pre-warmed $\left(37^{\circ} \mathrm{C}\right)$ maintenance medium. After washing, $2 \mathrm{ml}$ of overlay medium was added and the infected OMK monolayers incubated for 10 days at $37^{\circ} \mathrm{C}$. The overlay medium was then removed and monolayers were stained $(0.1 \%$ crystal violet in $37 \%$ formaldehyde). Plates were washed with distilled water, dried in air, and plaques were counted on a light box. Each experiment was independently repeated three times.

\section{Animals}

Male athymic nude (Nude-Foxn $1^{n u / n u}$ ) mice (Harlan Laboratories) were received at four weeks of age and allowed to acclimate for one week before experimentation. Mice were individually housed in clear polycarbonate cages under a 12 hour/12 hour light/dark cycle. Food and water was available ad libitum. All animal housing conditions, manipulations and treatments were performed in accordance with the protocols approved by the Institutional 
Animal Care and Use Committee of Western Michigan University (IACUC protocol number 13-07-01).

\section{Choice of cell line for tumor xenografts in nude mice}

Before initiating in vivo studies in athymic nude mice, we determined which hCRC cell line had the highest viral productivity when infected with TPV/egfp. TPV/ egfp was assayed for its ability to replicate in four hCRCderived cell lines: HCT 116, WiDr, SW1463 and COLO 205. OMK cells were used as a positive control. Each cell line was seeded into 12-well tissue culture plates and 0.1 $\mathrm{pfu} / \mathrm{cell}$ TPV/egfp inoculated into each well. Lysates were collected at 4 days post-infection and assayed by plaque assay, as described earlier. Each experiment was independently repeated three times.

\section{Tumor induction and measurement}

Tumors were produced in athymic nude mice by subcutaneous injection of $5 \times 10^{6} \mathrm{HCT} 116$ cells on the dorsal surface, approximately above the first lumbar vertebra. Each injection was followed by an assessment of viability by trypan blue exclusion to ensure that the cells were viable at and after the time of injection. Once visible, tumors were measured using a digital caliper (Pittsburgh, model 6ZBTMCO) along the major axis (length), minor axis (width) and $\mathrm{z}$ dimension (height), which were substituted into the formula volume $=($ length $) \times($ width $) \times($ height $) \times$ $(\pi / 6)$. When tumor size reached or surpassed $75 \mathrm{~mm}^{3}$ the animal was randomly segregated into the control group or one of the seven experimental virotherapy groups.

\section{Virotherapy of HCT 116 xenografts in nude mice}

Each treatment group was composed of five or six tumor-bearing athymic nude mice. A single virotherapeutic injection was administered once tumor volume reached or exceeded $75 \mathrm{~mm}^{3}$. Virotherapeutic injections were given intratumorally as a single injection of $5 \times 10^{6}$ pfu suspended in $100 \mu \mathrm{l}$ of crude OMK cell lysate diluted in normal saline. The control consisted of animals which received the HCT 116 cells but experienced only a mock virotherapeutic injection (100 $\mu$ l of vehicle only). This group is referred to as the mock virotherapy group. Mouse weights and tumor volumes were measured and recorded at three-day intervals thereafter. Data were collected for 13 time points over a total of 39 days. To control for unanticipated inflammation or other injection effects produced by the administration of the virotherapeutic injection, a vehicle control group was used.

\section{Immunohistochemistry preparation}

Formalin fixed specimens were processed, embedded in paraffin and sectioned on a rotary microtome at $4 \mu \mathrm{m}$. Sections were placed on adhesive slides and dried at $56^{\circ} \mathrm{C}$ overnight. The slides were subsequently deparaffinized in xylene and hydrated through descending grades of ethanol to distilled water. Slides were placed in Tris buffered saline $\mathrm{pH} 7.5$ for 5 minutes. Slides were then heat treated (in a rice steamer for 30 minutes followed by 10 minutes at room temperature, or in Pascal Pressure Cooker for 15 minutes at $125^{\circ} \mathrm{C}$ followed by $80^{\circ} \mathrm{C}$ for 5 minutes and then 30 minutes at room temperature on countertop) or underwent enzyme induced epitope retrieval $(10 \mathrm{mi}-$ nutes at $37^{\circ} \mathrm{C}$ ). These processes were followed by subsequent rinses and blocking for endogenous peroxidase using 3\% hydrogen peroxide/methanol bath (1:4 ratio) for 20 minutes at room temperature followed by running tap and distilled water rinses. Following pretreatments, standard avidin - biotin complex staining steps were performed at room temperature on a Dako Autostainer rinsing with Tris buffered saline + Tween 20 between all staining steps in protocol. Slides were blocked for nonspecific protein binding with Normal Goat or Rabbit Serum (Vector Labs - Burlingame, CA, USA) for $30 \mathrm{mi}-$ nutes. Endogenous Biotin was blocked by incubation in Avidin D (Vector) and D-Biotin (SigmaAldrich - St.Louis, MO, USA) for 15 minutes in each reagent. Primary antibodies, rabbit polyclonal anti-CD3 (AbD Serotec, Raleigh $\mathrm{NC}$ ), rat anti-mouse - F4/80 (Abcam Cambridge, MA), and rabbit polyclonal anti-caspase 3 (Abcam, Cambridge MA) were diluted in normal antibody diluent (Scytek Logan, UT, USA) and incubated for 1 hour at room temperature. Biotinylated rabbit anti-rat IgG $\mathrm{H}+\mathrm{L}$ (mouse absorbed) (Vector) diluted $5 \mathrm{ug} / \mathrm{ml}$ or goat antirabbit and IgG $\mathrm{H}+\mathrm{L}$ (Vector) diluted $11 \mathrm{ug} / \mathrm{ml}$ for 30 minutes and R.T.U. VectaStain Elite $A B C$ reagent (Vector) for an additional 30 minutes. Reactions were developed with Nova Red (Vector) for 15 minutes; followed by counter-stain in Gill 2 hematoxylin (Richard Allen Kalamazoo, MI, USA) for 15 seconds, differentiated in 1\% aqueous glacial acetic acid and rinsed in running tap water. Slides were then dehydrated through ascending grades of ethanol, cleared through several changes of xylene, and cover-slipped using flotex permanent mounting medium.

\section{Histological analyses}

In order to assess the validity of this cell transplant system the slides prepared above were used to determine the presence of tumor cells, as well as the nature of the immune response. Several key criteria were subjectively assessed; these criteria included the presence and form of the neoplastic cell line, evidence of cell death, extent and form of accumulating and infiltrating host inflammatory cells, degrees of fibrosis, and overall distribution of the infiltrating host cells within the tissues.

\section{Microscopy and image capture}

Slides were reviewed using brightfield microscopy on a Nikon Eclipse 80i microscope (Tokyo, Japan) with Nikon 
Plan 10x objective lens (N.A. 0.25) and Plan Fluor 40x objective lens (N.A 0.75). Images were taken using MetaMorph (Sunnyvale, CA, USA) imaging software and Qimaging (Surrey, BC, Canada) MicroPublisher Color Camera using the 10x objective lens. Scale bars were applied to the images using MetaMorph using calculated length per pixel specific for the camera and the objective lens. All scale bars were set to $200 \mu \mathrm{m}$.

\section{Statistics}

To assess treatment effects each experimental group was compared to the mock virotherapy control using the Mann-Whitney $U$ test (sometimes referred to as the Wilcoxon rank-sum test). Virotherapeutic treatment was considered to have produced a significant therapeutic effect if the average tumor volume at a specific time point and within a group was significantly reduced when compared to the mock-virotherapy control. A significance level of $\mathrm{p}<0.05$ was used throughout the study.

\section{Results}

\section{The p2KO vector and recombinant viruses}

During the transfection/infection, punctuate expression of the fluorescent reporter was evident in the OMK cell monolayer by five days post-transfection, indicating gene expression from the $\mathrm{p} 2 \mathrm{KO}$ vector in the cytosolic compartment of cells infected with wild-type TPV. In control cultures which were transfected with the p2KO vector but not subsequently inoculated with wild-type TPV, no fluorescence was observed, demonstrating that expression of viral genes did not occur in the absence of viral infection. After $3 \mathrm{X}$ plaque purification the absence of wild-type TPV DNA in the viral sample was verified by PCR using the recombinant viral genomic DNA as the template. All viral DNA samples were probed for the presence of the ampicillin resistance gene, which was not detected in any recombinant virus (data not shown). This indicates that all of the recombinant viruses resulted from a double-crossover event rather than a single-crossover event. The TPV $/ \Delta 2 L / \Delta 66 R / f l i C$ virus required a second iteration of transfection/infection and plaque purification.

The selection of recombinant viral plaques and the subsequent visualization of viral infection in cultured cells was greatly facilitated by the inclusion of the fluorescent reporters mCherry $\left(\lambda_{\mathrm{ex}} / \lambda_{\mathrm{em}}=587 \mathrm{~nm} / 610 \mathrm{~nm}\right)$ or enhanced green fluorescent protein $\left(\lambda_{\mathrm{ex}} / \lambda_{\mathrm{em}}=475 \mathrm{~nm} /\right.$ $509 \mathrm{~nm})$. Furthermore, the use of two fluorescent reporters made it possible to identify and isolate the double-ablated recombinant virus with the $f l i C$ insertion (TPV/ $\Delta 2 L / \Delta 66 R / f l i C$ ). A viral plaque at 2,4 and 6 days post-infection produced by the TPV $/ \Delta 2 L / \Delta 66 R / f l i C$ in an OMK cell monolayer is shown in Figure 3, and demonstrates the simultaneous expression of the brilliant orange-red and green color associated with mCherry and EGFP, respectively. A total of seven recombinant viruses

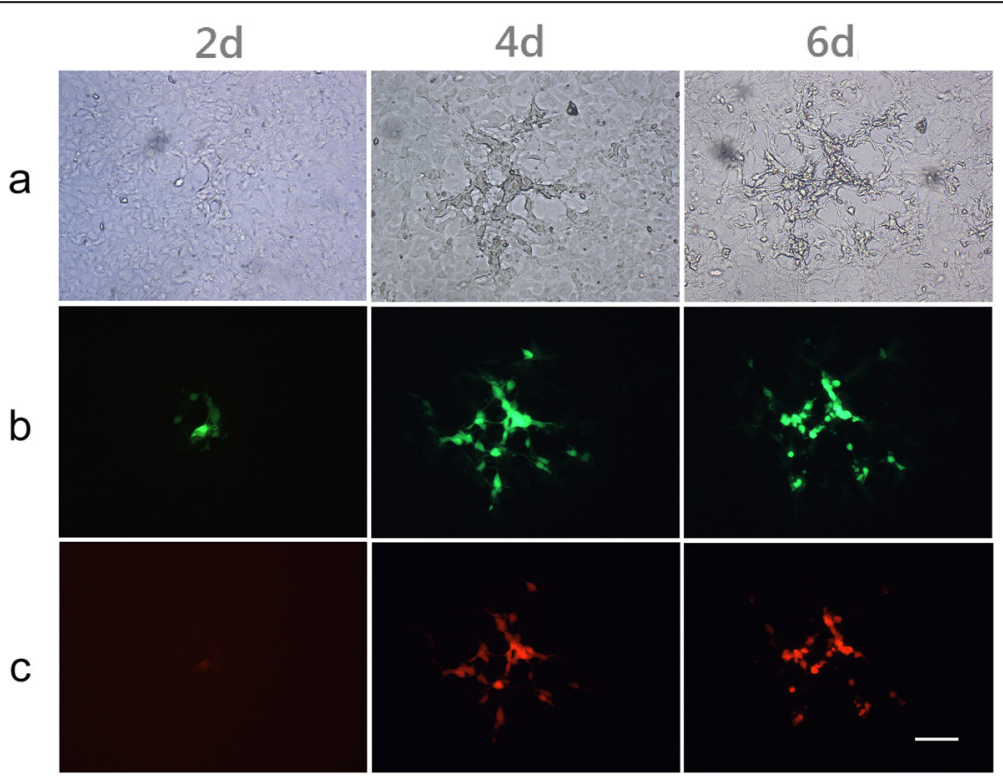

Figure 3 The recombinant virus TPV/ $\mathbf{6} 66 R / \Delta 2 \mathrm{~L} /$ fliC in culture. The plaque morphology associated with the TPV as visualized using the fluorescent reporters EGFP and mCherry present in the recombinant ablated for both $66 R$ and $2 L$, the TPV/ $66 R / \Delta 2 L / f l i C$. (a) A phase contrast view of the plaque in an OMK cell monolayer at days 2, 4 and 6 post-infection, visualized in white light. (b) The same plaque viewed at excitation and emission wavelengths which allow EGFP to be visualized. (c) The same plaque viewed at excitation and emission wavelengths which allow mCherry to be visualized. Microscope used was a Nikon Diaphot, total magnification 400X, exposed for 1.5 seconds. Image capture was performed with QImaging color camera using MetaMorph software (version 7.6.0.0, Molecular Devices). Scale bar $=100 \mu \mathrm{m}$. 
were generated. These include: TPV/egfp, TPV/ $\Delta 66 R$, $\mathrm{TPV} / \Delta 66 R / \mathrm{mGM}-C S F, \mathrm{TPV} / \Delta 66 R / \mathrm{m} M C P-1$, TPV/ $666 R /$ fliC, TPV/ $\Delta 2 L$, TPV/ $2 L / \Delta 66 R / f l i C$ (Table 2).

\section{Confirmation of viral transgene expression}

Before the start of in vivo experiments, we first demonstrated that the inserted ORFs were expressed in cells infected with the recombinant viruses $\mathrm{TPV} / \triangle 66 \mathrm{R} / \mathrm{mCCL2}$, $\mathrm{TPV} / \Delta 66 R / \mathrm{mGM}-C S F$ and TPV $/ \Delta 2 L / \Delta 66 R / f l i C$. OMK monolayers in $60 \mathrm{~mm}$ dishes were inoculated with the relevant recombinant virus (10 pfu/cell) and assayed for transgene expression in cell lysates and culture supernatants as described in the Methods. A Western blot of infected cell lysates from OMK cells inoculated TPV/ $\triangle 2 L /$ $\Delta 66 R / f l i C$ was probed with a monoclonal anti-FliC antibody (Figure 4). A single band was observed, identical to the FliC positive control (purified FliC), as expected. The intensity of this band gradually increased between day three and day six post-infection. The FliC transgene was not detected in cells infected with the recombinant TPV containing only the empty vector and/or any virus not expressing FliC.

Since the inserted mCCL2 and mGM-CSF ORFs contained the eukaryotic secretion signal sequence, infected cells were assayed for the presence of MCCL2 and mGM-CSF both in infected cell supernatants and cell lysates. Both transgenes were highly expressed and present in large amounts in infected cell supernatants ( $4.9 \mathrm{ng} / \mathrm{ml} \mathrm{mCCL2}$, and greater than $10.0 \mathrm{ng} / \mathrm{ml} \mathrm{mGM-}$ CSF) as assayed by ELISA. Both mGM-CSF and mCCL2 were only weakly detectable or undetectable in cytoplasmic extracts of infected cells, and in control uninfected cells or in cells infected with viruses not expressing these transgenes. These results indicated that both mCCL2 and mGM-CSF were secreted from infected cells, as anticipated, while FliC accumulated within the cytoplasm of infected cells over the course of the infection.

\section{Cell density determinations and virus replication}

Each cell line used in this study had its confluent density (cells $/ \mathrm{cm}^{2}$ ) determined at near confluence (as described in the Methods). Our control cell line, OMK, had a confluent density of approximately $1.0 \times 10^{5} \mathrm{cells} / \mathrm{cm}^{2}$. The densities determined for the human colorectal cancer cell lines were as follows: HCT 116 had a confluent density of approximately $1.4 \times 10^{5} \mathrm{cells} / \mathrm{cm}^{2}$; COLO205 had a confluent density of approximately $6.9 \times 10^{5}$ cells/ $\mathrm{cm}^{2}$; SW1463 had a confluent density of approximately $4.5 \times 10^{5}$ cells $/ \mathrm{cm}^{2}$; WiDr had a confluent density of approximately $2.5 \times 10^{5}$ cells $/ \mathrm{cm}^{2}$. These values were used to calculate the number of pfu to use when inoculating these cell lines for virus susceptibility assays. All cell lines supported virus replication. Almost all cells in the monolayers were lysed by day 10 following virus infection, as expected since TPV is a cytolytic virus.

Before initiating in vivo studies in athymic nude mice, we determined which hCRC cell line had the highest viral productivity when infected with TPV/egfp, as described in the Methods. OMK cells were the best host cells, allowing the production of approximately $3 \times 10^{6}$ progeny pfu/well $\left(9.5 \mathrm{~cm}^{2}\right)$. Of the hCRC cell lines tested, HCT 116 produced the most progeny virions with an average yield $(n=3)$ of approximately $7 \times 10^{5}$

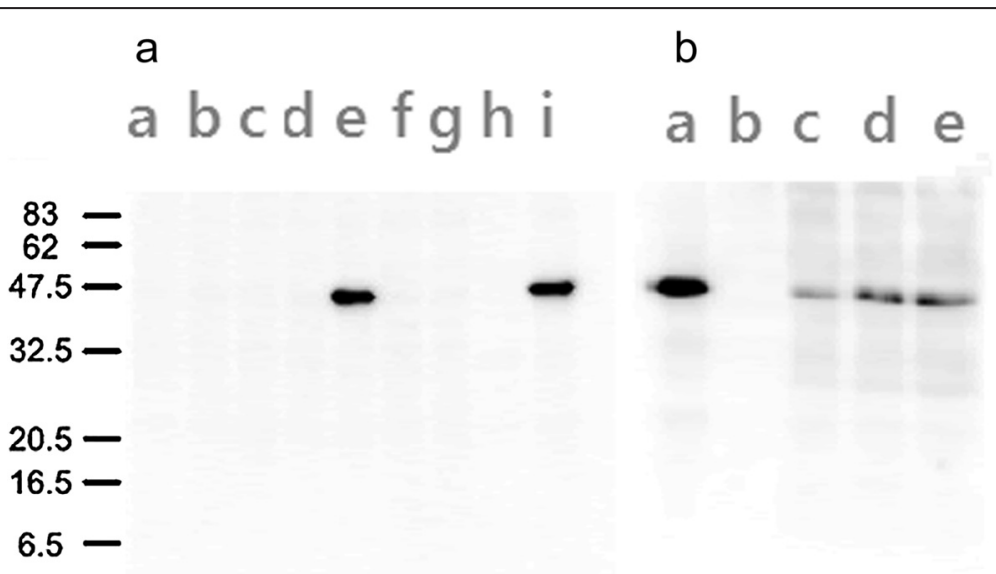

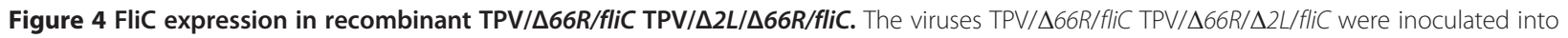
$60 \mathrm{~mm}$ dishes onto semi-confluent OMK cells at $10 \mathrm{pfu} / \mathrm{cell}$ and cytoplasmic extracts at 3, 5 and 6 days post-infection were subjected to $12 \%$ SDS-PAGE and Western blot analysis using a monoclonal antibody against FliC and a secondary anti-mouse HRP conjugated antibody. Visualization of bands was by ECL. Gel (a) lanes (a) mock infected, day 0; (b) mock infected, day 3; (c) wild-type TPV; (d) TPV/ $666 R$, the "empty vector" control;

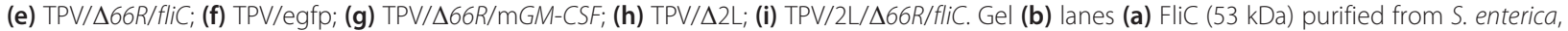

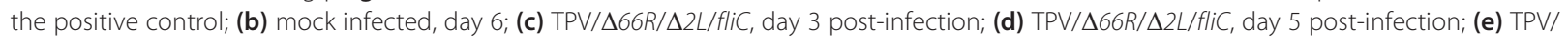
$\Delta 66 R / \Delta 2 L / f l i C$, day 6 post-infection. 
progeny pfu/well. We therefore chose the cell line HCT 116 for the in vivo phase of this study.

\section{Virotherapy HCT 116 xenografts in nude mice}

In order to evaluate the oncolytic potential of TPV recombinants, we induced HCT 116 tumors in athymic nude mice (Nude-Foxn $1^{n u / n u}$ ). Viability counts of HCT 116 cells from rapidly-dividing cultures demonstrated that $>99 \%$ were viable at the time of injection. Tumors generally reached $75 \mathrm{~mm}^{3}$ within one to three weeks after implantation of HCT 116 cells. Comprehensive virotherapeutic results are shown in Figure 5. Virotherapy
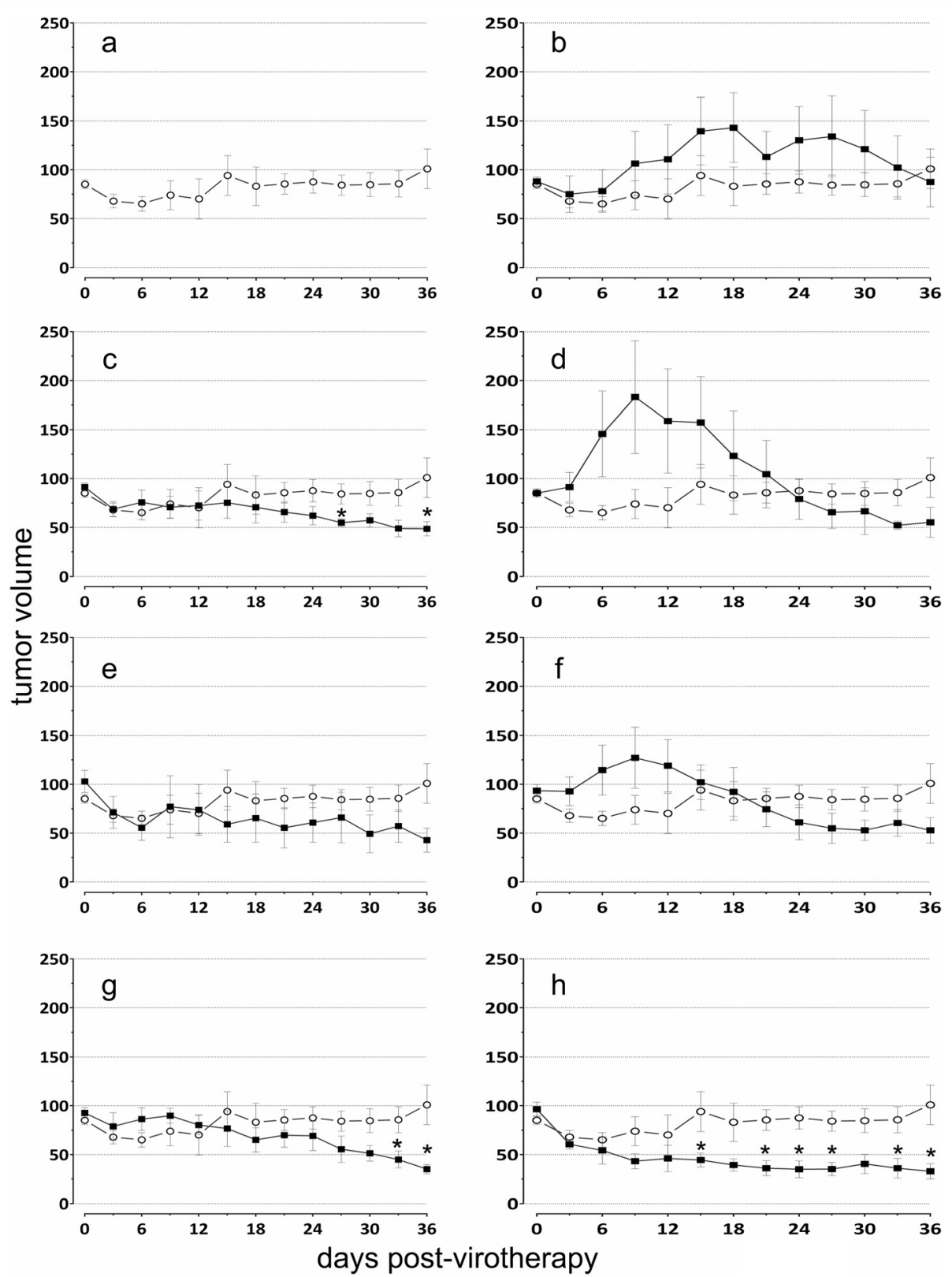

Figure 5 Virotherapy. Tumors were induced by subcutaneous injection of $5 \times 10^{6} \mathrm{HCT} 116$ cells onto the dorsal surface of athymic nude mice. In each group $n=5$ or 6 mice. Mice were randomly segregated into the control or experimental groups when tumor size reached $75 \mathrm{~mm}^{3}$. In each graph the $y$-axis is tumor volume $\left(\mathrm{mm}^{3}\right)$ and the $x$-axis is time (days post virotherapeutic injection). (a) A single mock injection containing $100 \mu$ l of vehicle only or recombinant virus was administered at day 0 and tumor volume was measured at three-day intervals. Tumor volume was calculated using the formula (length) $\times($ width $) \times($ height $) \times(\pi / 6)$. Average tumor volume is shown (black filled squares for each experimental group). Bars show the standard error of the mean $( \pm 1$ SEM). Points indicated with an asterisk (*) are significantly reduced from the control $(p \leq 0.05)$. (a) Mock virotherapeutic injection (vehicle only, open gray circles). This is the group to which all experimental groups were compared to test for OV virotherapeutic effect upon average

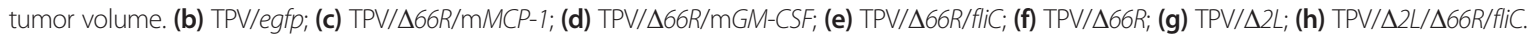


with TPV $/ \triangle 66 R$ (Figure 5f), TPV/ $\Delta 2 L$ (Figure $5 \mathrm{~g}$ ), and $\mathrm{TPV} / \Delta 2 L / \Delta 66 R / f l i C$ (Figure $5 \mathrm{~h}$ ) all produced significant reductions in tumor size at two or more time points when compared to the mock-injected controls. TPV/ $\Delta 2 L$-treated tumors were significantly smaller than mockinjected tumors at two time points, 33 days (a $47.6 \%$ reduction) and 36 days (a $65.2 \%$ reduction) post-treatment. $\mathrm{TPV} / \Delta 66 R$-treated tumors were significantly smaller than mock-injected tumors at two time points, 27 days (a $34.9 \%$ reduction) and 36 days (a $52 \%$ reduction) posttreatment. TPV $/ \Delta 2 L / \Delta 66 R / f l i C$-treated tumors showed a robust and durable virotherapeutic effect and were significantly reduced in volume when compared to mock-injected tumors at six time points, 15 days (a $56.1 \%$ reduction), 21 days (a $62.0 \%$ reduction), 24 days (a $63.8 \%$ reduction), 27 days (a $59.5 \%$ reduction), 33 days (a $55.3 \%$ reduction) and 36 days (a $69.6 \%$ reduction) after virotherapeutic treatment.

\section{Histological validation of the tumor model}

The primary neoplastic cell type was seen to be present in all samples examined; the cellular and nuclear morphology of this cell type varied distinctively between samples. The degree of necrosis and evidence of damage to this cell type varied from group to group and was clearly associated with caspase positivity and a range of morphological forms including nuclear pyknosis, cell ghosting, swelling, and vacularisation of the cells, were evident (Figure 6). The size of the tumors, as well as the proportion of viable to necrotic tumor cells also varied between samples. There were varied degrees of lymphocytic (CD3) and macrophage (F480) host responses to the presence of the tumor masses, with the greatest accumulation of these two cell types at the interface of the host and tumor tissue areas. Macrophages and scattered lymphocytes were seen invading the main tumor tissue areas in a relatively small number of samples.

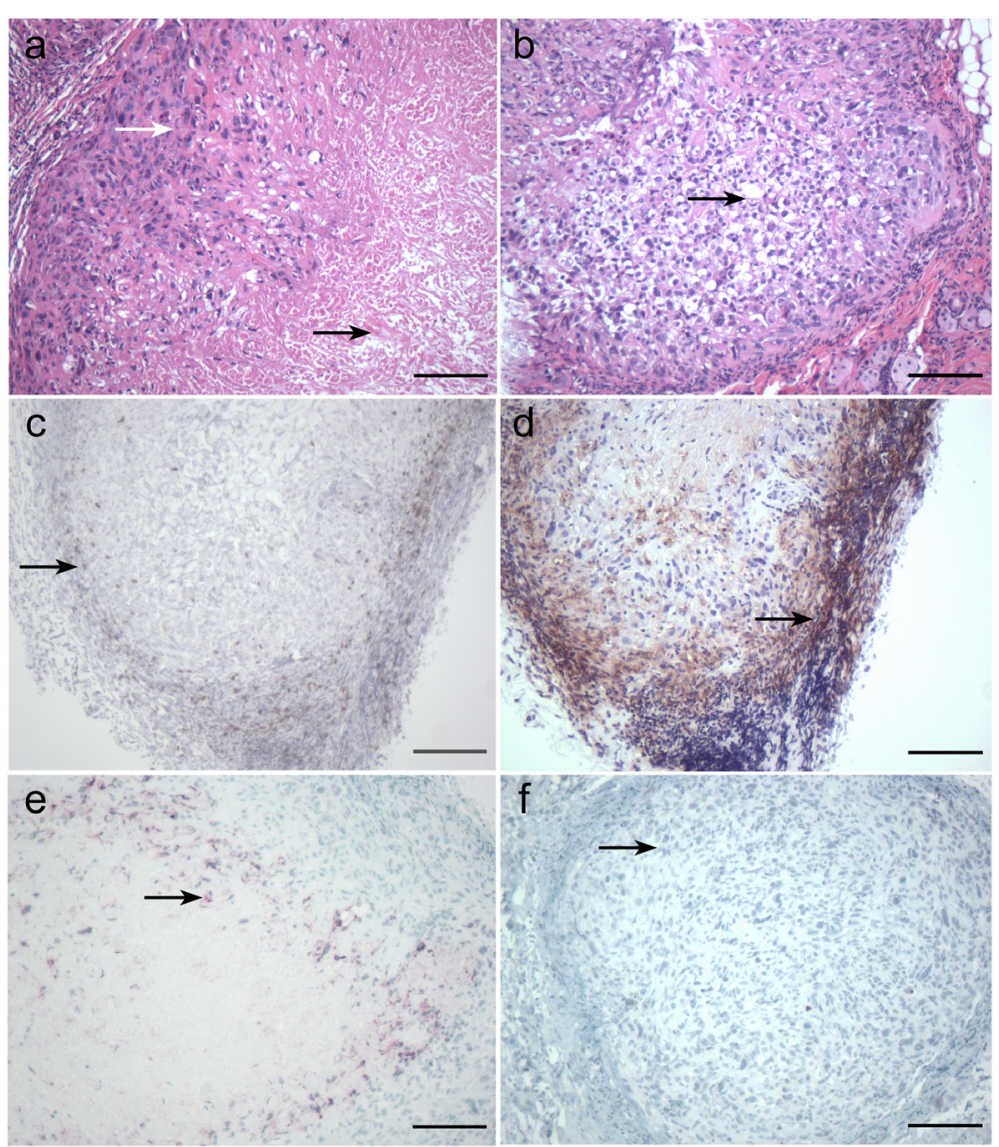

Figure 6 Histology of tumors. (a) H\&E stained tumor with healthy neoplastic cell ring (white arrow) around the necrotic tumor center (black arrow); (b) H\&E stained tumor with areas of tumor cell vacuolation and althered morphology (black arrow); (c) CD3 stained tumor showing lymphocytic infiltration in host-tumor interface (black arrow); (d) F4/80 stained tumor showing macrophage response (black arrow) including infiltration into the tumor mass; (e) Caspase stained tumor showing areas of caspase activity (black arrow) within tumor associted with the pale-staining necrotic area; (f) Caspase staining of a tumor free of cellular necrosis tumor showing the lack of caspase activity associated with healthy neoplastic cells (black arrow). All bars $200 \mu \mathrm{m}$ 


\section{Discussion}

Two of the major problems associated with the use of viruses for the treatment of cancers include (a) the absence of immune tolerance for an oncolytic virus, which will ultimately result in a strong antiviral immune response, and (b) person-to-person transmission of the therapeutic OV. In the absence of an effective immune tolerance strategy, it will be necessary to have a number of oncolytic viruses available for a serial treatment strategy and TPV should, therefore, be considered as a potential addition. The safety issue mainly deals with human-tohuman transmission. Again, unlike some other potential oncolytic viruses, TPV has not been reported to transmit from person to person.

Wild-type viruses from some families possess a degree of native oncoselectivity, most notably the reoviruses, vesicular stomatitis Indiana virus, and the Newcastle disease virus [61]. This selectivity arises from their ability to exploit defects in the cellular antiviral defenses commonly found in cancerous cells but absent in nontransformed cells. Examples of such defects include inappropriately activated Ras and the resulting reduction and/or loss of PKR activity exploited by reovirus [62-64] and the reduction and/or loss of the type I interferon response and subsequent failure to activate the PKR antiviral response [65-68], which is responsible for the cancer cell selectivity shown by the vesicular stomatitis Indiana virus.

In viruses without significant native oncospecificity, genetic engineering has been employed to increase cancer cell selectivity. Although some preference for cancerous and/or transformed cells has been shown in oncolytic variants of VACV [69], wild-type poxviruses are not generally considered to have a high degree of native oncospecificity. Ablation of the thymidine kinase gene in VACV has been shown to increase its cancer cell selectivity $[70,71]$. We therefore made TPV recombinants in which the thymidine kinase gene (66R) was ablated in an attempt to increase the oncoselectivity of the TPV. Although mice are not normally receptive animal hosts for TPV replication, it was important to demonstrate that the ablation of the $66 R$ gene did not result in a non-replicative virus in permissive cells (such as HCT 116 tumor cells).

We also made viruses ablated for the $2 L$ gene, the gene product of which is $2 \mathrm{~L}$ (formerly referred to as TPV-gp38), a protein with TNF-binding activity [21-23]. In a normal TPV infection, secreted $2 \mathrm{~L}$ acts to blunt the host inflammatory and antiviral immune response by binding to and effectively reducing the amount of TNF present. While this is a desirable outcome for the virus, when TPV is used as an OV it may be advantageous to increase, rather than decrease, the amount of inflammation at the tumor site. Currently the literature is divided regarding the role of inflammation upon tumor destruction and clearance [72,73]. In a hypothetical human patient whose tumor is treated with an OV based upon TPV, we hypothesize that the ablation of the $2 L$ gene may result in an effective increase in TNF concentration at the tumor site, which may ultimately act to increase tumor clearance. Because we have previously shown that the TPV $2 \mathrm{~L}$ binds to human TNF but not mouse TNF [22], the ablation of $2 \mathrm{~L}$ in some of the recombinant viruses described here was not expected to be a significant factor in tumor clearance. Additionally, we did not find any significant differences in TNF levels in the sera of any mice used in this study when assayed by ELISA (results not shown). We have nevertheless included $2 L$-ablated recombinants in this study because the testing of an $\mathrm{OV}$ in xenografted athymic nude mice is an important step towards further testing in more relevant primate models of cancer virotherapy.

Direct viral cytolysis (rather than tumor cell destruction by the host immune response) is of critical importance to tumor clearance in some cases [74], but viral cytolysis is only one of many factors impinging upon tumor survival and clearance, and immune cell recruitment can also play a critical role [75,76]. Because TPV is a new entrant into the field of oncolytic poxviruses, we tested wild-type TPV expressing EGFP with no other modifications (TPV/egfp) against a panel of human colorectal cancer cell lines to select the cell line which allowed the best viral replication, thereby maximizing the effect of direct viral tumor cell lysis. The hCRC cell lines tested for TPV/egfp replication were HCT 116, COLO205, SW1463 and WiDr. Although HCT 116 produced fewer progeny virions than the control cell line OMK, HCT 116 was by far the most productive of the hCRC cell lines tested. Many OVs have been characterized in tumors induced with HCT 116 [32]. The expression of TLR-5 has been demonstrated in HCT 116 cells [77]. For these reasons we selected HCT 116 for further characterization of the oncolytic potential of TPV recombinants in vivo.

We induced tumors in athymic nude mice with the HCT 116 cell line. One significant difference between our experience and many published studies [78,79] which used the same cell line was that our HCT 116induced tumor xenografts did not increase in volume to the expected level during virotherapy. However, we did observe the development of multiple secondary tumors in these mice. The precise reason behind this observation is difficult to evaluate. The shedding, high-motility and invasiveness of HCT 116 cells [80] may have been contributing factors. Furthermore, this has been shown in an HCT 116 orthotopic xenotransplant model [81], in which ex vivo HCT 116 tumors were subserosally implanted onto the ceca and ascending colon of $32 \mathrm{Balb} / \mathrm{c}$ 
nude male mice, and ultimately metastasized to distant locations, including invasion to liver, lung, as well as both liver and lung. Figure 5a shows the observed tumor development (from the point at which the tumor mass exceeded $75 \mathrm{~mm}^{3}$ ) in athymic nude mice xenografted with $5 \times 10^{6}$ HCT 116 cells and subsequently given only mock virotherapy. The average tumor volume consistently increased until approximately 15 days post virotherapy, at which point its volume stabilized at between $100-200 \mathrm{~mm}^{3}$ in most animals. This is in contrast to some previous studies which have shown that untreated HCT 116 tumors in nude mice gradually increase in volume over the same interval, when using similar numbers of HCT 116 cells in the initial xenograft. For example, it has been reported that HCT 116induced tumors have a doubling time of approximately 8 days [78]. Also, a recent study which examined the VACV as an OV therapeutic against HCT 116 xenografts in nude mice showed HCT 116 tumor growth up to $4000 \mathrm{~mm}^{3}$ in a time interval almost identical to ours [32].

Histological analyses of the tumors and associated tissue from all animals showed that the primary neoplastic cell type of the HCT 116 cell line was present in all the samples (Figure 6a). The cellular and nuclear morphology of this cell type varied distinctly between samples (Figure 6a, 6b). The degree of necrosis, or evidence of damage to this cell type, varied from group to group. Some cell death was clearly associated with caspase positivity (Figure 6e, 6f) and took a range of morphological forms, including; nuclear pyknosis, cell ghosting, swelling, and vacularisation (Figure $6 \mathrm{~b}$ ) of the cells. The size of the tumors, as well as the proportion of viable to necrotic tumor cells also varied between samples. There were substantial and varied lymphocytic (Figure 6c) and macrophage (Figure 6d) host responses to the presence of tumor masses, with scattered lymphocytes invading the main tumor tissue in a relatively small number of samples.

The addition of the $\mathrm{fliC}$ transgene in a doubleknockout background ( $\triangle 66 R$ and $\Delta 2 L$ ) resulted in the most efficacious $\mathrm{OV}$ in this study, producing more significantly-reduced tumor volumes and doing so at earlier times than any other recombinant TPVs tested. As stated above, the single-knockout virus (66R/thymidine kinase deleted) which expressed FliC approached but did not achieve a significant level of efficacy. TPV which was $\Delta 2 L$ with no other modifications (Figure $5 \mathrm{~g}$ ) or which expressed FliC in a $\Delta 66 R$ background (Figure $5 \mathrm{e}$ ) both trended towards significance but did not approach the efficacy of the TPV/ $\triangle 2 L / \Delta 66 R / f l i C$ virus (Figure $5 \mathrm{~g}$ ). It may be possible that the absence of $2 \mathrm{~L}$ somehow enabled the virus to persist longer within the tumor environment, since we detected virus in excised tumors only in the $2 L$ knockout viruses (data not shown).

If the presence of FliC did indeed contribute to the observed reduction in tumor size, then the mechanism by which this occurred is an open question. As a highlyconserved pathogen-associated molecular pattern (PAMP), bacterial flagellins are important targets for detector molecules involved in immunosurveillance. For example, detection of flagellin by the Nod-like receptor NCLR4 (also known as Ipaf) triggers activation of the Ipaf inflammasome [82] which in turn activates caspase1 and maturation of the cytokine interleukin $1 \beta$ (IL-1 $\beta$ ) in macrophages [83]. Although the expected amount of FliC produced during the course of an $\mathrm{OV}$ infection would be small, even minute amounts of bacterial flagellin $(\leq 5 \mu \mathrm{g} /$ animal $)$ administered to mice by tail vein injection causes global (i.e., in both organs and plasma) elevations of the cytokines TNF, IL- $1 \beta$, IL- 6 , and the chemokine MIP-2 (IL-8), as well as changes in the MEK intracellular signaling pathway [84]. Further, TPV is a cytolytic virus, therefore infected cells are lysed resulting in the release of the virally encoded FliC into the extracellular environment whereby it may trigger the activation of TLR5 and subsequent release of the previously mentioned inflammatory cytokines. Despite the current imperfect understanding flagellin's mechanism of action in mammalian cells, further research with OVs expressing this potent activator of the innate immune response should be performed. However, we have provided evidence that the activation of the innate immune response by TPV expressing FliC does contribute to the reduction of tumor mass. This observation is significant because the innate immune response is functionally intact in nude mice.

Our results demonstrate that the virus ablated for both $2 L$ and $66 R$ which expressed the $f l i C$ transgene produced a robust and durable therapeutic effect upon HCT 116 tumor xenografts in athymic nude mice. Both of the single-knockout viruses (TPV/ $\Delta 66 R$ or TPV/ $\Delta 2 L$ ) showed statistically significant reductions in tumor volume at least two time points, and in each case the observed significant reduction in tumor volume was temporally distant from the point of virotherapeutic inoculation. Both viruses definitely appeared to trend towards an effect at these later points. Indeed, with the exception of the TPV/egfp virus, all recombinant viruses tested appeared to produce some degree of tumor ablation, but only the viruses mentioned above produced a statistically significant effect. It may be that large intra-group variability masked our ability to detect virotherapeutic potency in this experiment. If this is indeed the case, then perhaps all of the recombinant viruses tested here are largely reliant upon direct cytolysis to promote tumor regression in this model, but the expression of FliC may expedite the response. More animals per group and a more typical rate of tumor growth should alleviate this problem in future studies. Since the $\mathrm{T}$ cell-dependent adaptive immune response is severely impaired in nude mice, the experiments described in 
this study suggests that the innate immune response has potentially contributed to the reduction of tumor burden. Additionally, Rhee et al. [55] have clearly demonstrated that injecting soluble FliC into human colorectal tumors xenografted in nude mice resulted in significant reduction in tumor mass. This effect was not observed when MyD88 and/or TLR-5 knockout cells were used. Furthermore, vaccinia virus GLV-1 h153 another poxvirus, has recently been shown to effectively reduce the human colorectal tumor burden in nude mice orthotopically xenografted [85]. Taken together our results strongly support the notion that TPV armed with FliC has potential to be an effective oncolytic virus which mediates its antiviral efficacy via both viral cytolysis and innate immune activation through TLR-5.

\section{Competing interests}

The authors declare that they have no competing interest.

\section{Authors' contributions}

Conceived and designed the study: KE. Performed molecular biological experiments: SC, EK, DJ, ME. Performed animal studies: SC, EK. Performed histopathological experiments and analyses: CN, RE, CM. Provided and constructed FliC and related plasmids: BT. Wrote and revised paper: SC, KE, $\mathrm{CN}$. All authors reviewed the manuscript. All authors read and approved the final manuscript.

\section{Acknowledgments}

We are grateful to Dr. Grant McFadden for the plasmid from which we cloned the mGM-CSF ORF; Dr. John Barrett for the plasmid pLing and Dr. Joshua Naranjo for suggestions pertaining to the statistical analyses of the data; Amy S. Porter and Kathleen A. Joseph for the immunohistochemistry and H\&E preparations. This study was supported by an NIH grant (1R15CA156262-01) to KE.

\section{Author details}

'Laboratory of Virology, Department of Biological Sciences, Western Michigan University, Kalamazoo, Ml 49008, USA. ²Department of Pathobiology and Diagnostic Investigation, Michigan State University, East Lansing, Michigan, USA.

Received: 21 November 2014 Accepted: 29 January 2015

Published online: 19 February 2015

\section{References}

1. American Cancer Society. Cancer Facts \& Figures 2014. Atlanta: American Cancer Society; 2014. p. 2014.

2. Siegel R, Jiemin R, Zhaohui Z, Jemal A. Cancer statistics, 2014. CA Cancer J Clin. 2014;63:11-30.

3. Jemal A, Bray F, Center MM, Ferlay J, Ward E, Forman D. Global cancer statistics. CA Cancer J Clin. 2011;61:69-90.

4. Taylor I. Liver metastases from colorectal cancer: lessons from past and present clinical studies. Br J Surg. 1996;83:456-60.

5. Weiss L, Grundmann E, Torhorst J, Hartveit F, Moberg I, Eder M, et al. Haematogenous metastatic patterns in colonic carcinoma: an analysis of 1541 necropsies. J Pathol. 1986;150:195-203.

6. Society AC. Colorectal Cancer Facts \& Figures 2011-2013. Atlanta: American Cancer Society; 2011. p. 2011.

7. Sinkovics J, Horvath J. Natural and genetically engineered viral agents for oncolysis and gene therapy of human cancers. Arch Immunol Ther Exp (Warsz). 2008;56 Suppl 1:3s-59s.

8. Martuza R, Malick A, Markert J, Ruffner K, Coen D. Experimental therapy of human glioma by means of a genetically engineered virus mutant. Science. 1991;252:854-6.

9. Guan M, Romano G, Coroniti R, Henderson EE. Progress in oncolytic virotherapy for the treatment of thyroid malignant neoplasm. J Exp Clin Cancer Res. 2014;33:91.
10. Kirn D. Clinical research results with dl1520 (Onyx-015), a replication-selective adenovirus for the treatment of cancer: what have we learned? Gene Ther. 2000;8:89-98.

11. Toyoda E, Doi R, Kami K, Mori T, Ito D, Koizumi M, et al. Midkine promoterbased conditionally replicative adenovirus therapy for midkine-expressing human pancreatic cancer. J Exp Clin Cancer Res. 2008;27:30.

12. Kemeny N, Brown K, Covey A, Kim T, Bhargava A, Brody L, et al. Phase I, open-label, dose-escalating study of a genetically engineered herpes simplex virus, NV1020, in subjects with metastatic colorectal carcinoma to the liver. Hum Gene Ther. 2006;17:1214-24.

13. Geevarghese S, Geller D, de Haan H, Hörer M, Knoll A, Mescheder A, et al. Phase I/II study of oncolytic herpes simplex virus NV1020 in patients with extensively pretreated refractory colorectal cancer metastatic to the liver. Hum Gene Ther. 2010;21:1119-28.

14. Breitbach C, Burke J, Jonker D, Stephenson J, Haas A, Chow L, et al. Intravenous delivery of a multi-mechanistic cancer-targeted oncolytic poxvirus in humans. Nature. 2011;477:99-102.

15. Kirn D, Wang Y, Liang W, Contag C, Thorne S. Enhancing poxvirus oncolytic effects through increased spread and immune evasion. Cancer Res. 2008;68:2071-5.

16. Maitra R, Ghalib M, Goel S. Reovirus: a targeted therapeutic-progress and potential. Mol Cancer Res. 2012;10:1514-25.

17. Le Boeuf F, Bell J. United virus: the oncolytic tag-team against cancer! Cytokine Growth Factor Rev. 2009;21:205-11.

18. Smith $G$, Moss B. Infectious poxvirus vectors have capacity for at least 25 000 base pairs of foreign DNA. Gene. 1983;25:21-8.

19. Johnston JB, McFadden G. Poxvirus immunomodulatory strategies: current perspectives. J Virol. 2003;77(11):6093-100

20. Isaacs S, Kotwal G, Moss B. Vaccinia virus complement-control protein prevents antibody-dependent complement-enhanced neutralization of infectivity and contributes to virulence. Proc Natl Acad Sci U S A. 1992;89:628-32.

21. Paulose M, Bennett B, Manning A, Essani K. Selective inhibition of TNF-alpha induced cell adhesion molecule gene expression by tanapox virus. Microb Pathog. 1998;25:33-41.

22. Brunetti C, Paulose-Murphy M, Singh R, Qin J, Barrett J, Tardivel A, et al. A secreted high-affinity inhibitor of human TNF from Tanapox virus. Proc Natl Acad Sci U S A. 2003;100:4831-6.

23. Rahman M, Jeng D, Singh R, Coughlin J, Essani K, McFadden G. Interaction of human TNF and beta2-microglobulin with Tanapox virus-encoded TNF inhibitor, TPV-2L. Virology. 2009;386:462-8.

24. Shimamura T, Jeng D, Lucas A, Essani K. Suppression of neointimal hyperplasia following angioplasty-induced vascular injury in pigs infected with swinepox virus. The open virology journal. 2011;6:91-6.

25. Nazarian S, Barrett J, Stanford M, Johnston J, Essani K, McFadden G. Tropism of Tanapox virus infection in primary human cells. Virology. 2007;368:32-40.

26. Downie A, Taylor-Robinson CH, Caunt AE, Nelson GS, Manson-Bahr PE, Matthews TC. Tanapox: a new disease caused by a pox virus. Br Med J. 1971;1:363-8.

27. Jezek Z, Arita I, Szczeniowski M, Paluku KM, Ruti K, Nakano JH. Human tanapox in Zaire: clinical and epidemiological observations on cases confirmed by laboratory studies. Bull World Health Organ. 1985;63:1027-35.

28. Park BH, Hwang T, Liu TC, Sze DY, Kim JS, Kwon HC, et al. Use of a targeted oncolytic poxvirus, JX-594, in patients with refractory primary or metastatic liver cancer: a phase I trial. Lancet Oncol. 2008;9:533-42.

29. Hengstschläger M, Knöfler M, Müllner EW, Ogris E, Wintersberger E, Wawra E. Different Regulation of Thymidine Kinase during the Cell Cycle of Normal Versus DNA Tumor Virus-Transformed Cells. J Biol Chem. 1994;269:13836-42.

30. Alegre, M., Robison, R., and K. O'Neill. Thymidine kinase 1 upregulation is an early event in breast tumor formation. J Oncol. 2012. doi. doi:10.1155/2012/575647

31. Broët $P$, Romain $S$, Daver A, Ricolleau G, Quillien V, Rallet A, et al. Thymidine kinase as a proliferative marker: clinical relevance in 1,692 primary breast cancer patients. J Clin Oncol. 2001;19:2778-87.

32. Ehrig K, Kilinc MO, Chen NG, Stritzker J, Buckel L, Zhang Q, et al. Growth inhibition of different human colorectal cancer xenografts after a single intravenous injection of oncolytic vaccinia virus GLV-1 h68. J Transl Med. 2012;11:79-15.

33. Merrick A, llett E, Melcher A. JX-594, a targeted oncolytic poxvirus for the treatment of cancer. Current opinion in investigational drugs (London, England: 2000). 2009;10:1372-82.

34. Cattaneo R, Miest T, Shashkova E, Barry M. Reprogrammed viruses as cancer therapeutics: targeted, armed and shielded. Nat Rev Microbiol. 2008;6:529-40. 
35. Kaur B, Cripe T. E. Chiocca E. 'Buy one get one free': armed viruses for the treatment of cancer cells and their microenvironment. Curr Gene Ther. 2009;9:341-55.

36. Kennedy JD, Pierce CW, Lake JP. Extrathymic T cell maturation. Phenotypic analysis of $\mathrm{T}$ cell subsets in nude mice as a function of age. J Immunol. 1992;148:1620-9.

37. Rahimi P, Wang CY, Stashenko P, Lee SK, Lorenzo JA, Graves DT. Monocyte chemoattractant protein-1 expression and monocyte recruitment in osseous inflammation in the mouse. Endocrinology. 1995;136:2752-9.

38. Homey B, Steinhoff M, Ruzicka T, Leung D. Cytokines and chemokines orchestrate atopic skin inflammation. J Allergy Clin Immunol. 2006;118:178-89.

39. Nickel R, Beck L, Stellato C, Schleimer R. Chemokines and allergic disease. J Allergy Clin Immunol. 1999;104:723-42.

40. Parker J, Meleth S, Hughes KB, Gillespie GY, Whitley RJ, Markert JM. Enhanced inhibition of syngeneic murine tumors by combinatorial therapy with genetically engineered HSV-1 expressing CCL2 and IL-12. Cancer Gene Ther. 2005;12:359-68.

41. Parmiani G, Castelli C, Pilla L, Santinami M, Colombo MP, Rivoltini L. Opposite immune functions of GM-CSF administered as vaccine adjuvant in cancer patients. Ann Oncol. 2007:18:226-32.

42. Eager R, Nemunaitis J. GM-CSF gene-transduced tumor vaccines. Mol Ther. 2005;12:18-27.

43. Dranoff G. GM-CSF-based cancer vaccines. Immunol Rev. 2002;188:147-54.

44. Hege $K$, Jooss K, Pardoll D. GM-CSF gene-modified cancer cell immunotherapies: of mice and men. Int Rev Immunol. 2005;25:321-52.

45. Higano CS, Corman JM, Smith DC, Centeno AS, Steidle CP, Gittleman M, et al. Phase 1/2 dose-escalation study of a GM-CSF-secreting, allogeneic, cellular immunotherapy for metastatic hormone-refractory prostate cancer. Cancer. 2008;113:975-84

46. Janke M, Peeters B, de Leeuw $\mathrm{O}$, Moorman $\mathrm{R}$, Arnold A, Fournier $\mathrm{P}$, et al. Recombinant Newcastle disease virus (NDV) with inserted gene coding for GM-CSF as a new vector for cancer immunogene therapy. Gene Ther. 2007:14:1639-49.

47. Varghese S, Rabkin S. Oncolytic herpes simplex virus vectors for cancer virotherapy. Cancer Gene Ther. 2002:9:967-78.

48. Kim J, Oh J, Park B, Lee D, Kim J, Park H, et al. Systemic armed oncolytic and immunologic therapy for cancer with JX-594, a targeted poxvirus expressing GM-CSF. Mol Ther. 2006. doi:10.1016/j.ymthe.2006.05.008

49. Burke J, Lamm D, Meng M, Nemunaitis J, Stephenson J, Arseneau J, et al. A first in human phase 1 study of CG0070, a GM-CSF expressing oncolytic adenovirus, for the treatment of nonmuscle invasive bladder cancer. J Urol. 2012. doi:10.1016/j.juro.2012.07.097

50. McQuiston J, Parrenas R, Ortiz-Rivera M, Gheesling L, Brenner F, Fields PI. Sequencing and comparative analysis of flagellin genes fliC, fljB, and flpA from Salmonella. J Clin Microbiol. 2004;42:1923-32.

51. Beatson S, Minamino T, Pallen M. Variation in bacterial flagellins: from sequence to structure. Trends Microbiol. 2006;14:151-5.

52. Yoon S, Kurnasov O, Natarajan V, Hong M, Gudkov AV, Osterman AL, et al. Structural basis of TLR5-flagellin recognition and signaling. Science. 2012:335:859-64.

53. Sun YH, Rolán H, Tsolis R. Injection of flagellin into the host cell cytosol by Salmonella enterica serotype Typhimurium. J Biol Chem. 2007:282:33897-901.

54. Mogensen T. Pathogen recognition and inflammatory signaling in innate immune defenses. Clin Microbiol Rev. 2009;22:240-73.

55. Rhee SH, Im E, Pothoulakis C. Toll-Like receptor 5 engagement modulates tumor development and growth in a mouse xenografts model of human colon cancer. Gastroenterology. 2008;135:518-28.

56. Chakrabarti S, Sisler JR, Moss B. Compact, Synthetic, Vaccinia Virus Early/Late Promoter for Protein Expression. Biotechniques. 1997;23:1094-7.

57. Boyle D, Coupar B, Both G. Multiple-cloning-site plasmids for the rapid construction of recombinant poxviruses. Gene. 1984:35:169-77.

58. Mackett M, Smith G, Moss B. General method for production and selection of infectious vaccinia virus recombinants expressing foreign genes. J Virol. 1984;49:857-64.

59. Isaacs SN. Vaccinia Virus and Poxvirology: Methods and Protocols. (Methods in Molecular Biology). New Your, New York, USA: Humana Press; 2012.

60. Mediratta S, Essani K. The replication cycle of tanapox virus in owl monkey kidney cells. Can J Microbiol. 1998;45:92-6.

61. Everts $\mathrm{B}$, van der Poel H. Replication-selective oncolytic viruses in the treatment of cancer. Cancer Gene Ther. 2005;12:141-61.

62. Vähä-Koskela M, Heikkilä J, Hinkkanen A. Oncolytic viruses in cancer therapy. Cancer Lett. 2007:254:178-216.
63. Coffey M, Strong J, Forsyth P, Lee P. Reovirus therapy of tumors with activated Ras pathway. Science (New York, NY). 1998;282:1332-4

64. Comins C, Heinemann L, Harrington K, Melcher A, De Bono J, Pandha H. Reovirus: viral therapy for cancer "as nature intended". Clinical oncology (Royal College of Radiologists (Great Britain)). 2008;20:548-54.

65. Barber G. Vesicular stomatitis virus as an oncolytic vector. Viral Immunol. 2003;17:516-27.

66. Hastie E, Grdzelishvili V. Vesicular stomatitis virus as a flexible platform for oncolytic virotherapy against cancer. J Gen Virol. 2012;93:2529-45.

67. Fiola C, Peeters B, Fournier P, Arnold A, Bucur M, Schirrmacher V. Tumor selective replication of Newcastle disease virus: association with defects of tumor cells in antiviral defense. Int J Cancer. 2006;119:328-38.

68. Critchley-Thorne R, Simons D, Yan N, Miyahira AK, Dirbas FM, Johnson DL, et al. Impaired interferon signaling is a common immune defect in human cancer. Proc Natl Acad Sci U S A. 2009;106:9010-5.

69. Kelly K, Woo Y, Brader P, Yu Z, Riedl C, Lin SF, et al. Novel oncolytic agent GLV-1 h68 is effective against malignant pleural mesothelioma. Hum Gene Ther. 2008;19:774-82

70. Zeh H, Bartlett D. Development of a replication-selective, oncolytic poxvirus for the treatment of human cancers. Cancer Gene Ther. 2002;9:1001-12.

71. Parato K, Breitbach C, Le Boeuf F, Wang J, Storbeck C, Ilkow C, et al. The oncolytic poxvirus JX-594 selectively replicates in and destroys cancer cells driven by genetic pathways commonly activated in cancers. Mol Ther. 2012;20:749-58.

72. Balkwill F, Mantovani A. Inflammation and cancer: back to Virchow? Lancet. 2001;357:539-45

73. Tsuchiyama T, Nakamoto Y, Sakai Y, Mukaida N, Kaneko S. Optimal amount of monocyte chemoattractant protein-1 enhances antitumor effects of suicide gene therapy against hepatocellular carcinoma by M1 macrophage activation. Cancer Sci. 2008;99:2075-82.

74. Weibel S, Raab V, Yu YA, Worschech A, Wang E, Marincola FM, et al. Viralmediated oncolysis is the most critical factor in the late-phase of the tumor regression process upon vaccinia virus infection. BMC Cancer. 2010;11:68

75. Prestwich RJ, Errington F, Diaz RM, Pandha HS, Harrington KJ, Melcher AA, et al. The case of oncolytic viruses versus the immune system: waiting on the judgment of Solomon. Hum Gene Ther. 2009;20:1119-32.

76. Cerullo V, Pesonen S, Diaconu I, Escutenaire S, Arstila P, Ugolini M, et al. Oncolytic adenovirus coding for granulocyte macrophage colony-stimulating factor induces antitumoral immunity in cancer patients. Cancer Res. 2010;70:4297-309.

77. Zhao L, Kwon MJ, Huang S, Lee JY, Fukase K, Inohara N, et al. Differential modulation of Nods signaling pathways by fatty acids in human colonic epithelial HCT116 cells. J Biol Chem. 2007;282:11618-28.

78. Céspedes MV, Espina C, Garcia-Cabezas AM, Trias M, Gomez de Pulgar MT, et al. Orthotopic Microinjection of Human Colon Cancer Cells in Nude Mice Induces Tumor Foci in All Clinically Relevant Metastatic Sites. Am J Pathol. 2007;170:1077-85.

79. Wang Z, Cook T, Alber S, Liu K, Kovesdi I, Watkins SK, et al. Adenoviral gene transfer of the human inducible nitric oxide synthase gene enhances the radiation response of human colorectal cancer associated with alterations in tumor vascularity. Cancer Res. 2004;64:1386-95.

80. Wang J, Sun L, Myeroff L, Wang X, Gentry L, Yang J, et al. Demonstration that mutation of the type II transforming growth factor beta receptor inactivates its tumor suppressor activity in replication error-positive colon carcinoma cells. J Biol Chem. 1995;270:22044-9.

81. Rajput A. Dominguez San Martin I, Rose R, Beko A, Levea C, Sharratt E, et al. Characterization of HCT116 human colon cancer cells in an orthotopic model. J Surg Res. 2008;147:276-81.

82. Schroder K, Tschopp J. The inflammasomes. Cell. 2010;140:821-32.

83. Miao E, Alpuche-Aranda CM, Dors M, Clark AE, Bader MW, Miller SI, et al. Cytoplasmic flagellin activates caspase-1 and secretion of interleukin 1 beta via Ipaf. Nat Immunol. 2006;7:569-75.

84. Rolli J, Loukili N, Levrand S, Rosenblat-Velen N, Rignault-Clerc S, Waeber B, et al. Bacterial flagellin elicits widespread innate immune defense mechanisms, apoptotic signaling, and a sepsis-like systemic inflammatory response in mice. Critical care (London, England). 2009;14:R160.

85. Eveno C, Mojica K, Ady JW, Thorek DL, Longo V, Belin LJ, et al. Gene therapy using therapeutic and diagnostic recombinant oncolytic vaccinia virus GLV1 h153 for management of colorectal peritoneal carcinomatosis. Surgery. 2015;157(2):331-7. 